\title{
Medical writing: A Habit and Discipline We Need to Nurture Rishi Pokhrel ${ }^{1}$
}

${ }^{1}$ Department of Anatomy, Nepalese Army Institute of Health Sciences, Kathmandu, Nepal.

Medical writing is an integral part of clinical practice and research. It is needless to say "if you haven't written and published about it, you haven't done it in the first place". Each and every doctor around the world goes through the almost the same training in terms of how rigorous it is and its duration, but still we are unique in our own ways. It is this quality of being unique and innovative that develops the medical field forwards and paves the way for new research. It is our duty and obligation to share the new knowledge and experience that we have gained during our practice. The more we share, the more we learn and the more we learn the more we acquire new knowledge for ultimate good of mankind.

Regrettably, medical writing and publishing has taken a backstage in our part of the world. It is astonishing to see that we have many professors of medical world who don't have a single medical paper in their name. It is impossible to imagine the ocean of knowledge and experience that they posses of which the medical fraternity will be deprived of forever.

Things seem to change slowly and more medical professionals are keen now about writing and publishing their work than in the past. Regrettably again, this change seems to have imposed by their 'professional need' rather than their interest and keenness to share their experience. This is reflected in the correspondence with the authors who submit their manuscripts but are too busy to communicate about the same.

Medical Journal of Shree Birendra Hospital(MJSBH) is a forum for all involved in medical science; doctors, nurses and paramedics. Not only do we publish original research articles and case reports but also heartedly welcome and encourage communications like case series, personnel opinion, case reviews and letter to editor.

We also request our authors to meticulously go through 'author guidelines' of journal before preparing your manuscript. There are certain aspects, which sound very trivial, like 'font' and 'font size' but these simple factors may become decisive on weather the article gets accepted or rejected. More importantly check your emails regularly for any communications from the Journal.

Lastly, we invite all to submit their work to MJSBH.

Happy writing! 